\title{
NOTE ON A CASE OF TYPHOID FEVER, WITH RARE AND RAPIDLY FATAL COMPLICA- TIONS.
}

\author{
Br ALFRED R. PARSONS, M.B. Univ. Dubl., F.R.C.P.; \\ Physician to the City of Dublin Hospital.
}

[Read in the Section of Pathology, November 30, 1894.]

RichaRD B., aged twenty-two, by occupation a labourer, was admitted to the City of Dublin Hospital, under my care, on the 31st October, 1894, complaining of feeling ill and unable to work. His father and mother were both healthy, and his two sisters and two brothers were also in good health. He himself had never been ill previously. For ten or twelve days previously to admission he had been feeling poorly, and had been troubled with diarrhœea and some slight epistaxis.

On udmission, he complained chiefly of headache, vomiting, pains in the back and legs, and general weakness. Physical examination-'T. $105^{\circ}$, pulse 104 , respirations 28 ; but nothing abnormal was detected in his lungs or heart. There was no tenderness orer the abdomen, no distension, no spots, no enlargement of any organ, and the spleen was not palpable.

He was sponged with cold water, and the temperature fell from $105^{\circ}$, at 730 p.m., to $103 \cdot 2^{\circ}$ at 915 p.m. His urine was normal, except for a faint trace of albumen.

November 3rd.-Crepitant râles were audible over the front and back of his chest, and he was rather troubled with a cough which, he said, "shook" him very much. There was also some slight distension of the abdonien, and some half-dozen spots of an ill-defined character were visible.

For the first eight days after admission the bowels moved once or twice daily. As a rule, light coloured, formed motions were passed, but about the 21st day of his illness he became rather constipated and an enema was occrsionally necessary. He slept tolerably well at night, took two or three pints of milk and a pint of beef tea or cocoa daily; and although the pyrexia was rather severe, its tendency on the whole was downwards, from the time of 


\section{Case of Typhoid Fever, with Fatal Complications.}

his admission to hospital. His pulse, till the day before his death, never exceeded 108, and his respirations varied from 28 to 36 .

From the duration of his illness, and the absence of any distinct physical signs, I louked upon the case as one of typhoid fever; though I felt it was typhoid fever only by exclusion, and that, consequently, the diagnosis was not so certain as if based on positive signs.

From the 26th day of his illness the decline of his temperature was still more marked, so that on the morning of the 32 nd day his temperature was $97^{\circ}$. On that day he seemed very well and made no complaint at all, except for a little pain in his throat. An examination revealed slight enlargement of his left tonsil, and this, I thought, was quite sufficient to explain the pain. That evening the temperature rose to $1024^{\circ}$, but fell the following morning to $99^{\circ}$. His abdomen was examined again on the 33rd day of his illness; but nothing abnormal could be detected. His temperature, however, commenced to rise, and about 1 p.m. reached $105^{\circ}$. That evening I had a note from the resident medical pupil, $\mathbf{M r}$. William Croly, asking me to come round and see the patient at my earliest convenience, as he did not seem so well as in the morning. I went to the hospital about 730 and heard that, at 3 p.m., the patient had gone asleep, and awakened, some time after 4 p.m., with difficulty in breathing. His respirations were so loud that they could be heard at a distance of 15 or 20 yards. Dr. Palmer and my resident pupil examined his chest, but could find no pulmonary mischief to account for his dyspnoea. Hot, moist applications were tried, and seemed to give some temporary relief, but, as there was no distinct improvement, I was at once communicated with. On examination there was considerable dyspnoea, distinct laryngeal stridor, sucking in of suprasternal and supraclavicular spaces ; distinct, but feeble phonation, a temperature of $100.8^{\circ}$, pulse 140 , and respirations 50. He was rather pale, slightly livid about the lips, and sweating slightly on forehead. A hasty laryngoscopic examination, which, needless to say, was. made. with great difficulty, revealed an enormously swollen and brilliantly red epiglottis, with some yellowish material along its edges. It was manifest that an acute odema of the glottis had occurred, and that the only way by which relief could be afforded was a tracheotomy. Arrangements were at once made, and the senior surgeon, Mr. Henry Gray Croly, communicated with. Mr. Croly arrived in a few minutes and decided on performing the low operation, so as to get away, as far. 
as possible, from the laryngeal mischief. The trachea was situated deeply, and considerable venous hæmorrhage took place. On opening the trachea a distinct improvement in the patient's aspect was noticed, but each attempt at inserting the tube seemed to bring on a spasm of coughing. After the tube, on one occasion, had been worn for a few minutes, it was noticed that the tapes had become very tight. Presently the neck was found to be considerably swollen, the face became puffed and tympanitic, the upper part of the trunk showed a similar condition, and in a few hours the emphysema had extended down to Poupart's ligaments. The patient passed a restless night, the pulse became weaker and more frequent, and about 11 a.m. the following day the patient died.

'The post-mortem examination, which was made twelve hours after death, revealed such extensive swelling of the epiglottis and surrounding structures that the vocal cords, on looking into the larynx, were quite invisible. Along the lateral margins of the epiglottis was a greyish material which did not present the characters of a false membrane, but looked much more like a superficial necrosis, the result of a very acute inflanmation. When the parts were sufficiently pressed asunder to allow of a view of the vocal cords, it was found that they were quite normal. The tracheotomy wound was directly in the centre and quite free. The lungs were engorged with blood, and no abnormality was detected in the heart. In the abdomen, the spleen was somewhat enlarged and soft. The intestines seemed normal till within about two feet of the ileo-cæcal valve a small circular ulcer in a Peyer's patch was found. Two other ulcers, a little lower down, the larger of which was immediately above the valve, and about the size of a two-shilling piece, were present, and a few small circular ulcers were found in the large intestine. There was also distinct enlargement and congestion of the mesenteric glands.

The appearances at the autopsy, therefore, confirmed the clinical diagnosis of typhoid fever. The small amount of ulceration and, more especially, the shape of the ulcers, are not without interest. As a rule, typhoid ulcers are oval in shape and have their long axis in the length of the intestine, but, occasionally, they assume the circular form. (See plate accompanying the article on "Abdominal Typhus" in the Real Encyclopädie der gesammten Heilkunde.)

The most remarkable feature in this case was the sudden onset of acute laryngeal symptoms. Except slight hoarseness, 
most probably the result of a little catarrh, laryngeal complications in these countries are exceedingly rare. Murchison, with his enormous experience, met only three or four cases of ulceration of the larynx in typhoid fever, while on the Continent, Hoffmann states, it is present in 28 out of 250 cases. Zuelzer observed it in more than 20 per cent. of the fatal cases, and Griesinger found it present in 31 out of 118 autopsies. The condition has been described as perichondritis typhosa by Rokitansky. Liining states that æedema was present in ? out of 115 autopsies of enteric fever cases, in which there were serious laryngeal complications. With regard to the cause of these ulcers, different views have been held by various authors. Dr. Watson Williams succeeded in isolating the bacillus typhosus from one of these ulcers, and consequently believes that these lesions are to be looked upon as specific typhoid ulcers. This view has also been held by Rokitansky and Mackenzie, while Hilton Fagge and Murchison considered them rather as secondary lesions. Unfortunately, in this case, no cultures were made from the laryngeal ulcers, and, consequently, no conclusive evidence can be deduced as to their nature; but, so far as a microscopic examination of the diseased parts is of any weight, it goes to support the latter view, inasmuch as the sections present enormous numbers of micrococci.

The occurrence of emphysema is, I think, to be looked upon as one of those rare complications of a tracheotomy, the explanation of which is obscure; but, at the same time, it must be borne in mind that, in a few cases of typhoid fever, emphysema has occurred in which no tracheotomy was performed. It was Dr. Wilks who first satisfactorily explained this very rare condition, by pointing out an ulcer on the posterior part of the trachea, through which the air escaped into the tissues. It is, therefore, conceivable that the emphysema may, in this case, have happened quite independently of the operation. 
Dr. DAwson said that in his experience laryngeal complications in typhoid fever were not very rare. There was often a certain amount of sore throat. Ulcerations of two different types had been regarded as probable - one a diphtheritic ulceration, and the other, although this had not been conclusively proved, due to the typhoid bacillus. Its existence in the blood and its power of causing ulceration in the intestine was evident, and it was easy to imagine that it could cause ulceration elsewhere. The present case he did not think to be one of diphtheritic ulceration, judging from the sections of tissue removed from the larynx.

Dr. J. W. Moore, having inspected the ulcers present in the small intestine, said that as far as he could judge they were ulcers of typhoid fever, from which the sloughs had come away. $\mathrm{He}$ said he considered that sometimes portions of the system other than the intestines-as, for instance, the lungs-bore the brunt of the disease.

Mr. Croly, who had performed tracheotomy on the patient, said that never before in his experience had he met with a case of typhoid fever presenting this severe laryngeal complication, and, moreover, he had never been troubled with emphysema as a sequel to any tracheotomy he had previously done. In the performing of the operation he emphasised the importance of opening the trachea as soon as possible to cheek venous bleeding; of cutting a piece out of the trachea, not merely making a slit in it; and of scraping away the deep layer of the cervical fascia, lest it should form a sort of valve over the opening in the trachea, by the opening in the fascia not remaining exactly over the opening in the trachea. He had heard of a case in which this fact led to the death of the patient. He said he was nnable to explain the occurrence of the emphysema. There was nothing peculiar in this case previously except that the trachea was very deep.

Dr. Hawtrey Benson said that during his 27 years' experience in Baggot-street Hospital he had never met with a similar case.

Dr. Parsons, in replying, stated that Dr. Bewley had drawn his attention to a statement in Eulenberg's Encyclopædia of Practical Medicine, where it was alleged that twenty per cent. of the cases of typhoid which die had ulceration of the larynx. In a few cases extensive emphysema had been observed. 